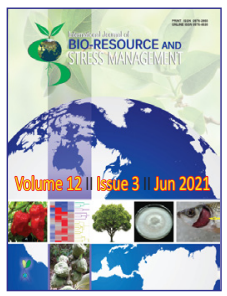

\title{
Bacterial Lipopolysaccharide Activates Toll-Like Receptor 2 and Toll-Like Receptor 4 Gene Expression in PBMC of Vechur Cattle
}

\author{
R. Lakshmi ${ }^{*}$, K. K. Jayavardhanan ${ }^{2}$, J. Thanislass ${ }^{3}$ and P. Visha ${ }^{1}$
}

${ }^{1}$ Dept. of Veterinary Physiology and Biochemistry, Veterinary College and Research Institute, Salem (636 112), India

${ }^{2}$ Dept. of Veterinary Biochemistry, College of Veterinary and Animal Sciences, Thrissur, Kerala (680 651), India

${ }^{3}$ Dept. of Veterinary Biochemistry, Rajiv Gandhi Institute of Veterinary Education \& Research, Puducherry (605 009), India

Corresponding Author
R. Lakshmi
e-mail: lakshmivetbio@gmail.com
Citation: Lakshmi et al., 2021. Bacterial
Lipopolysaccharide Activates Toll-Like Receptor 2
and Toll-Like Receptor 4 Gene Expression in PBMC of
Vechur Cattle. International Journal of Bio-resource
and Stress Management 2021, 12(3), 186-191.
HTTPS://DOI.ORG/10.23910/1.2021.2234.

Copyright: (C) 2021 Lakshmi et al. This is an open access article that permits unrestricted use, distribution and reproduction in any medium after the author(s) and source are credited.

Data Availability Statement: Legal restrictions are imposed on the public sharing of raw data. However, authors have full right to transfer or share the data in raw form upon request subject to either meeting the conditions of the original consents and the original research study. Further, access of data needs to meet whether the user complies with the ethical and legal obligations as data controllers to allow for secondary use of the data outside of the original study.

Conflict of interests: The authors have declared that no conflict of interest exists.

Funding: The research was conducted with the supports of Department of Science and Technology and College of Veterinary and Animal Science for providing the fund

Acknowledgement: The authors acknowledge College of Veterinary and Animal Science for providing the laboratory facilities for the successful completion of this work. The first author acknowledging the Department of Science and Technology for providing INSPIRE Fellowship (IF131025) for the Ph.D program

Article History

RECEIVED on $30^{\text {th }}$ March 2021

\begin{abstract}
Vechur cattle, an indigenous breed of Kerala and it is the smallest cattle breed in the world. They are highly disease resistant. The occurrence of mastitis is very Rare in this breed as compared to crossbred cattle. Rearing of these Vechur breed is more cost effective as they require less feed. Therefore, characterisation of factors involved in the immune system of these breeds might provide an insight into the mechanisms involved in the variation in disease resistance. Toll-like receptors (TLRs) are part of the innate immunity, can recognize the particular pathogens through Pathogen Associated Molecular pattern s (PAMPs) and play important roles in host defense. TLR2 and TLR4 important TLR mediate the responsiveness to bacterial lipopolysaccharide (LPS). Since Vechur cattle are less susceptible to mastitis, in vitro expression assay of TLRs were accessed by challenging the Peripheral Blood Mononuclear Cells (PBMC) with bacterial LPS. Treatment of PBMC with LPS, significantly increased TLR2 and TLR4 genes expression $(p \leq 0.01)$ in Vechur cattle breed when compared with that of control and crossbred cattle. Among the two TLRs studied, the relative expression of mRNA in Vechur cattle was relatively higher for TLR2 (6.90) than TLR4 (4.24). The higher expression of $T L R 2$ and TLR 4might contribute maximum innate immune response against the mastitis bacteria in Vechur cattle.
\end{abstract}

Keywords: TLRs, gene expression, LPS, PBMC, vechur

\section{Introduction}

Mastitis is the most prevalent and one of the economically imposing diseases in dairy cattle, commonly developed in response to intramammary bacterial infection (Seegers et al., 2003; Zuhair, 2017). Vechur cattle, a rare breed of Bos indicus, are an indigenous breed of Kerala state of India had shown less susceptibility to mastitis as compared to crossbreed cattle. Characterisation of factors involved in the immune system of Vechur breeds might provide an insight into the mechanisms involved in the variation in disease resistance. Toll-like receptors (TLRs) are part of the innate immunity, can recognize conserved pathogen associated molecular patterns (PAMPs) which is expressed on invading pathogens (Walletet al., 2018; Lemaitre et al., 1996; Aderema and Ulevitch, 2000; Akira et al., 2001), and provoke cytokine production 
and upregulation of co-stimulatory molecules in phagocytes, leading to the stimulation of T cells (Jianet al., 2016). Thus, TLRs play a pivotal role in linking the innate immunity through specific ligand binding of LPS which in turn promote antigenspecific acquired immunity as well (Vidya et al., 2018)

Bacterial lipopolysaccharide (LPS) is a complex glycolipid endotoxin composed of a hydrophobic domain known as lipid $A$ and a hydrophilic polysaccharide region important for most of the LPS-induced biological effects (Schletter et al., 1995; Yang et al., 1998; Weishan et al., 2017). LPS stimulates host cells such as monocytes, macrophages, and B cells through the activation of protein kinases and transcription factors. LPS recognition the key event in host antimicrobial defense reaction (Schletter et al., 1995; Ulevitch and Tobias, 1995; Anna et al., 2021). Among the mammalian TLRs, TLR2 had shown to mediate the signals of bacterial constituents, including lipoproteins, lipoteichoic acid, and lipopeptides, whereas TLR4 is found the major and predominant receptor for as at least some types of LPS, whereas TLR2 is expendable (Dziarski et al., 2001; Phileman et al., 2019).

In present in vitro experiment, the relative expression of TLR2 and TLR4 genes were accessed in Vechur cattle breed along with crossbreed cattle by challenging the PBMC with bacterial LPS.

\section{Materials and Methods}

\subsection{Experimental period and location}

The experiment was carried out during the year 2016 at College of Veterinary and Animal Sciences, Mannuthy Thrissur, Kerala.

\subsection{Collection of PBMCs and incubation}

The blood samples $(10 \mathrm{ml})$ were collected from three healthy Vechur and crossbreed cattle of 3 to 4 years of age using EDTA coated vacationer. PBMCs were isolated from blood using Ficoll-Paque (Sigma Aldrich) density gradient centrifugation. The cells were cultured in $8 \mathrm{ml}$ RPMI-1640 medium in tissue culture flasks by incubating in a $\mathrm{CO}_{2}$ incubator at $37^{\circ} \mathrm{C}$ for 3 hours. During the incubation period $80 \% \mathrm{RH}$ in an atmosphere of $5 \% \mathrm{CO}_{2}$ was maintained. After incubation, the medium was discarded along with the dead floating cells. The live monocytes cells which were anchored were used for the study.

\subsection{LPS induction of $P B M$ cells}

The isolated monocytes cells were incubated with the E.coli LPS (100 ng ml-1) for 2 hours in a $\mathrm{CO}_{2}$ incubator $\left(5 \% \mathrm{CO}_{2}\right.$ pressure) at $37^{\circ} \mathrm{C}(80 \% \mathrm{RH})$. Similar preparation of cells was subjected for incubation without the LPS, which served as control. At the end of the incubation period, the cells were harvested, and total RNA was isolated from the incubated samples (Thanislass et al., 2009)

\subsection{RNA isolation and reverse transcription}

Total RNA was isolated from PBMC by using TRIzol reagent (Sigma). The quality and quantity of extracted RNA was determined by agarose gel electrophoresis and NanoDrop Spectrophotometer (Thermo Scientific, USA) DNA contamination was removed from extracted total RNA by treatment with DNase 1.

\subsection{Complementary DNA (cDNA) synthesis}

First strand cDNA was synthesized from isolated RNA using RevertAid first strand cDNA synthesis kit (Thermo Scientific, K1622). The reactions were set up in $0.2 \mathrm{ml} \mathrm{PCR}$ tubes. Template RNA $5 \mu \mathrm{g}$, Oligo (dT) 18 primer $1.0 \mu \mathrm{l}$. 5X reaction buffer $4.0 \mu \mathrm{l}$, Ribolock $1 \mu \mathrm{l}$, dNTP mix $(10 \mathrm{mM}) 2.0 \mu \mathrm{l}$, Revert Aid $1.0 \mu \mathrm{l}$ and Nuclease free water. The contents of the tube were mixed gently and centrifuged briefly. For RT-qPCR, oligo (dT) 18 primer were used for cDNA synthesis, the reaction mix was incubated for 60 minutes at $42^{\circ} \mathrm{C}$. The reaction was terminated at $70^{\circ} \mathrm{C}$ for 5 minutes.

\subsection{Primers synthesis}

Primers used for RT-qPCR of TLR2, TLR4 and $\beta$-actin were designed using Primer 3 software from bovine mRNA sequence available in the NCBI database (Table 1). $\beta$-actin gene was selected as internal control gene.

Table 1: Primer sequence for TLR2, TLR4 and $\beta$-actin genes used in RT-qPCR

\begin{tabular}{llc}
\hline Name & Sequence $\left(5^{\prime} \rightarrow 3^{\prime}\right)$ & Product size \\
\hline TLR2 -RT-F & AGCGAGTGGTGCAAGTATGA & $114 \mathrm{bp}$ \\
TLR2 -RT-R & CTGGGGAATGGCCTTCTTGT & \\
TLR4-RT-F & GCCGTGGAGACAAACCTAGT & $138 \mathrm{bp}$ \\
TLR4-RT-R & CTCCAGGTTGGGCAGGTTAG & \\
$\beta$-actin-RT-F & CCACACCTTCTACAACGAGC & $105 \mathrm{bp}$ \\
$\beta$-actin-RT-R & ATCTGGGTCATCTTCTCACG & \\
\hline
\end{tabular}

\section{7. $P C R$ Standardization and $R T-q P C R$}

The PCR was carried out in volume of $12.5 \mu \mathrm{l}$ in $0.2 \mathrm{ml} \mathrm{PCR}$ tubes. The PCR was standardized for different gradients of temperatures. For RT-qPCR analysis, Maxima SYBER Green Master Mix (2X) with ROX (Thermo Scientific) were used and RT-qPCR reactions were performed using RT-qPCR system (ECO software). The qPCR mix was in a final volume of $12.5 \mu \mathrm{L}$ contained $6.25 \mu \mathrm{l}$ of Maxima SYBER green master mix, $1 \mu \mathrm{l}$ each of forward and reverse primer, $1 \mu$ of Template cDNA and $4.25 \mu \mathrm{l}$ of nuclease free water. The thermal profile included initial denaturation at $95^{\circ} \mathrm{C}$ for $10 \mathrm{~min}$, this was followed by 40 cycles of denaturation at $95^{\circ} \mathrm{C}$ for $30 \mathrm{~s}$, annealing at $58^{\circ} \mathrm{C}$ for $20 \mathrm{~s}$, extension at $72^{\circ} \mathrm{C}$ for $30 \mathrm{~s}$. A melt curve of the amplified products was acquired after the 40 cycles by a further run of $95^{\circ} \mathrm{C}$ for $15 \mathrm{sec}, 55^{\circ} \mathrm{C}$ for $15 \mathrm{sec}$ followed by $95^{\circ} \mathrm{C}$ for 15 sec to confirm the specificity of the amplified and absence of primer dimer. The $2^{-\Delta \Delta C T}$ method (Kumar et al., 2012). was used to determine the fold change of gene expression level.

\section{Results and Discussion}

Toll-like receptors are pledged for recognizing cognate ligands 
of pathogens such as LPS, resulting in the production of inflammatory responses that defend the host against invading pathogens (Salwa et al., 2019). The major receptors TLR2 and $T L R 4$ exhibit different specificities in the recognition of cell wall component of the bacteria. Although TLR2 functions as a receptor for certain exceptional LPS species (Dixon and Darveau, 2005) TLR4 is the primitive receptor for Gramnegative bacterial LPS and plays a prominent role in defense against infections (Takeuchi et al., 1999; Theodora et al., 2019). Since $T L R 2$ and TLR4 are the best competitors for bridging from the innate immunity of macrophages to the adaptive immunity of $\mathrm{T}$ and $\mathrm{B}$ lymphocytes, an understanding of their TLRs transcriptional expression and regulation in native macrophages in response to gram-negative bacteria is important (Bohan et al., 2019). In this study, we have

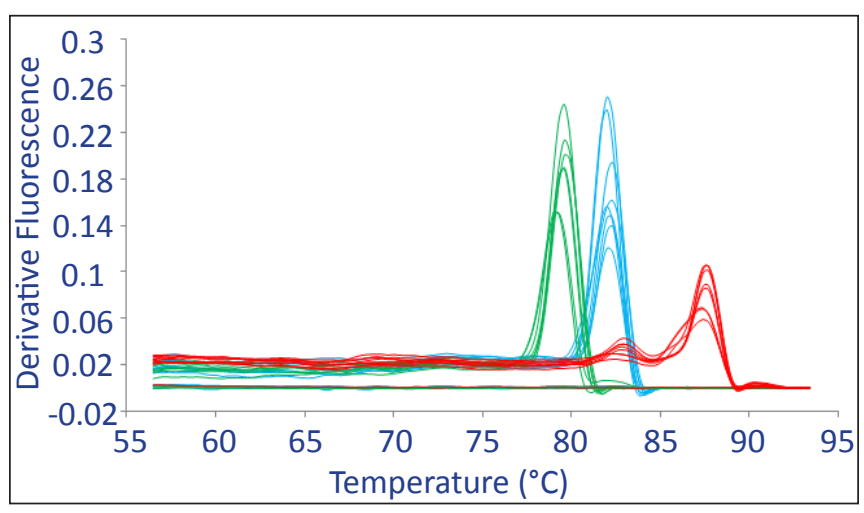

Figure 1: Melt curve plot for $B$-actin, TLR2 and TLR4 genes in LPS induction of in vitro assay

The mean values of $C_{q}, \Delta C_{q}, \Delta \Delta C_{q}$, and relative quantification for TLR2 gene in Vechur and crossbreed after LPS induction are given in Table 2. The relative expression of TLR2 was significantly $(p \leq 0.01)$ higher in the Vechur cattle (6.90 fold), explored the expression pattern of presumptive LPS signalling receptors TLR2 and TLR4 in PBMC of Vechur and Crossbred cattle. PBMC consists of various inflammatory cell populations that circulate between the vascular system and tissues and are likely to reflect disease status of an organ (Almeida et al., 2007). Since Vechur cattle are less susceptible to mastitis, the in vitro experiment assay $T L R$ s expression of this breed against mastitis was accessed by challenging the PBMC with LPS. The PBMCs of Vechur cattle were isolated and induced by culturing in presence of LPS in RPM1-1640 media. After culturing, RNA was isolated from the PBMCs and processed for gene expression assay by using RT-qPCR. Derivative melt curve and amplification plot for TLR2, TLR4and $\beta$-actin genes obtained by RT-qPCR are shown in Figure 1 and 2 .

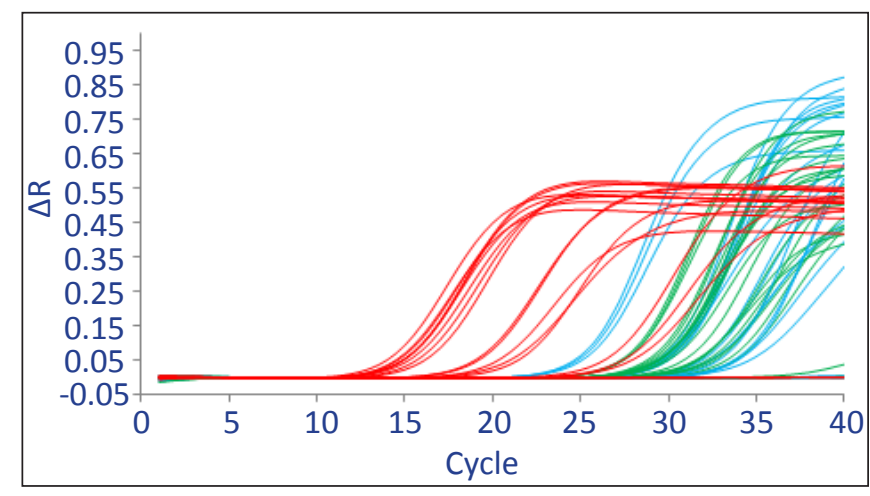

Figure 2: Amplification plot for B-actin, TLR2 and TLR4 genes in LPS induction of in vitro

and also significant ( $p \leq 0.05)$ in crossbred cattle (1.95 fold) as compared to control (Figure 3). Several studies reported that $T L R 2$ are capable of mediating LPS responsiveness (Kirschning) et al., 1998; Mastuguchi et al., 2000; Shimazu et al., 1999). Our

Table 2: Relative expression of TLR2 gene after LPS induction of in vitro

\begin{tabular}{|c|c|c|c|c|c|c|}
\hline \multirow{2}{*}{$\begin{array}{l}\text { Sample } \\
\text { Sample } \\
\end{array}$} & \multicolumn{2}{|c|}{ Cq Mean \pm SE } & \multirow[t]{2}{*}{$\Delta \mathrm{Cq}$} & \multirow[t]{2}{*}{$\Delta \mathrm{Cq}$ Mean } & \multirow[t]{2}{*}{$\Delta \Delta \mathrm{Cq}$} & \multirow[t]{2}{*}{$\mathrm{RQ}$} \\
\hline & $T L R 2$ & b-actin & & & & \\
\hline \multicolumn{7}{|c|}{ Cross breed } \\
\hline Control & $27.11 \pm 0.25$ & $14.44 \pm 0.27$ & 12.67 & $12.67 \pm 0.25$ & & \\
\hline Case 1 & $26.11 \pm 0.17$ & $14.06 \pm 0.04$ & 12.05 & & -0.62 & 1.54 \\
\hline Case 2 & $26.25 \pm 0.05$ & $14.27 \pm 0.07$ & 11.98 & & -0.69 & 1.62 \\
\hline \multirow[t]{2}{*}{ Case 3} & $25.45 \pm 0.79$ & $14.36 \pm 0.27$ & 11.10 & & -1.57 & 2.98 \\
\hline & & & & $11.71 \pm 0.31$ & -0.96 & $1.95 a^{\text {ns }}$ \\
\hline \multicolumn{7}{|c|}{ Vechur breed } \\
\hline Control & $29.53 \pm 0.20$ & $13.16 \pm 0.09$ & 16.37 & $16.37 \pm 0.20$ & & \\
\hline Case 1 & $26.32 \pm 0.06$ & $12.94 \pm 0.05$ & 13.38 & & -2.99 & 7.94 \\
\hline Case 2 & $26.57 \pm 0.20$ & $12.79 \pm 0.39$ & 13.78 & & -2.59 & 6.02 \\
\hline \multirow[t]{2}{*}{ Case 3} & $25.65 \pm 0.09$ & $12.06 \pm 0.54$ & 13.59 & & -2.78 & 6.87 \\
\hline & & & & $13.58 \pm 0.12$ & -2.79 & $6.90^{\mathrm{b}^{* *} \mathrm{c}^{* *}}$ \\
\hline
\end{tabular}

a: Cross breed vs Control; b: Vechur breed vs Control; c: Cross breed vs Vechur breed 


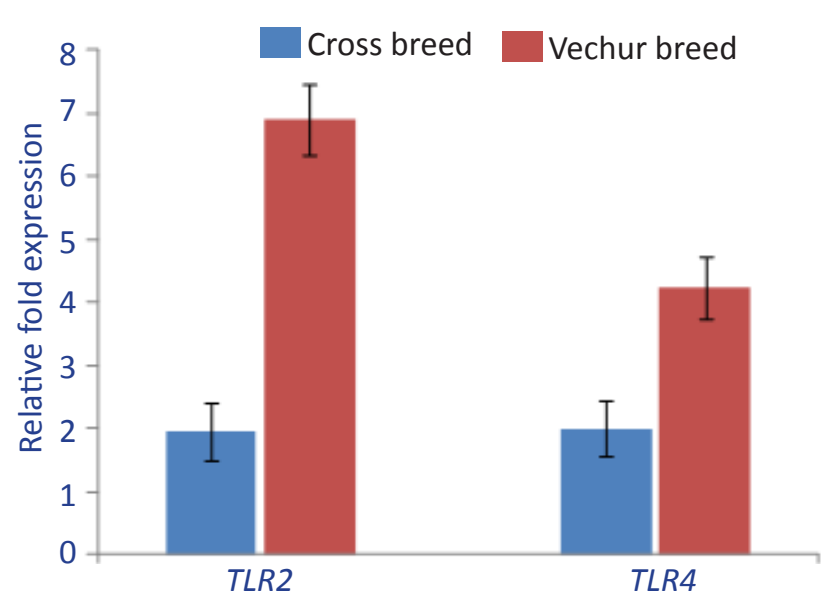

Figure 3: Relative expression of TLR2 and TLR4 genes in crossbreed and Vechur cattle

results are in agreement with Ibeagha-Awemuet al., 2008 who found that increased mRNA expression of TLR2 in mammary glands infected with LPS. Further, Yang et al., 2008 also found increased expression of TLR2 in mammary epithelial cells collected from diseased quarters of cows challenged with LPS. Medvedev et al., 2000 also described the rapid increase of TLR2 mRNA in LPS treated mouse macrophage. It has been noted that $T L R 2$, can be induced in macrophages in too response bacterial infections and expendable for the initial host responses against LPS, it may subsidize the stimulated macrophage responses seen at consecutive stages of infection (Mastuguchi et al., 2000). Although LPS is recognized to stimulate various kinase pathways, the activation of pathways does notseem to be crucial for the induction of TLR2 gene expression. Regulation of TLR2 expression may be one of the immune regulatory mechanisms commonly involved in host defence against many bacterial strains.

The mean values of $C_{q}, \Delta C_{q}, \Delta \Delta C_{q}$, and relative quantification for TLR4 gene in Vechur and cross breed after LPS induction are given in Table 3. Relative expression of TLR4 with LPS induction was found to be higher and significant $(p \leq 0.01)$ in Vechur cattle than Crossbred cattle (Figure 3). LPS has been reported to up-regulate $T L R 4$ in bovine mammary epithelial cells (Ibeagha-Awemu et al., 2008). Petzl et al., 2008 also reported increased expression of TLR4 in mammary tissue after experimental in vivo infection with $E$. coli. Similarly, mammary epithelial cells treated with $E$. coli bacteria esulted in up-regulation of TLR4 (Griesbeck-Zilch et al., 2008) Panigrahi et al., 2014 found that PBMC from crossbred cattle challenged with LPS showed a nearly double and statistically significant increase in mRNA expression of TLR4 when compared to control group. LPS from $E$. coli and other Gramnegative bacteria are recognized by TLR4 (Bohan et al., 2019; Poltorak et al., 1998). Inoculation of the mammary glands with bacterial LPS is adequate to activate an inflammatory

Table 3: Relative expression of TLR4 gene after LPS induction of in vitro ass

\begin{tabular}{|c|c|c|c|c|c|c|}
\hline \multirow{2}{*}{$\begin{array}{l}\text { Sample } \\
\text { Sample }\end{array}$} & \multicolumn{2}{|c|}{ Cq Mean \pm SE } & \multirow[t]{2}{*}{$\Delta \mathrm{Cq}$} & \multirow[t]{2}{*}{$\Delta$ Cq Mean } & \multirow[t]{2}{*}{$\Delta \Delta \mathrm{Cq}$} & \multirow[t]{2}{*}{$\mathrm{RQ}$} \\
\hline & TLR4 & B-actin & & & & \\
\hline \multicolumn{7}{|c|}{ Cross breed } \\
\hline Control & $27.11 \pm 0.25$ & $14.44 \pm 0.27$ & 12.67 & $12.67 \pm 0.25$ & & \\
\hline Case 1 & $25.25 \pm 0.20$ & $14.06 \pm 0.04$ & 11.19 & & -1.48 & 2.78 \\
\hline Case 2 & $26.58 \pm 0.25$ & $14.27 \pm 0.07$ & 12.31 & & -0.36 & 1.28 \\
\hline \multirow[t]{2}{*}{ Case 3} & $25.88 \pm 0.07$ & $14.36 \pm 0.27$ & 11.53 & & -1.14 & 2.21 \\
\hline & & & & & -0.96 & $1.99 a^{\mathrm{ns}}$ \\
\hline \multicolumn{7}{|c|}{ Vechur breed } \\
\hline Control & $29.53 \pm 0.20$ & $13.16 \pm 0.09$ & 16.37 & $11.68 \pm 0.33$ & & \\
\hline Case 1 & $27.39 \pm 0.42$ & $12.94 \pm 0.05$ & 14.45 & & -1.92 & 3.79 \\
\hline Case 2 & $27.23 \pm 0.13$ & $12.79 \pm 0.39$ & 14.45 & & -1.92 & 3.79 \\
\hline \multirow[t]{2}{*}{ Case 3} & $26.02 \pm 0.95$ & $12.06 \pm 0.54$ & 13.96 & $16.37 \pm 0.20$ & -2.41 & 5.30 \\
\hline & & & & $14.29 \pm 0.16$ & -2.08 & $4.24^{b^{* *} c^{* *}}$ \\
\hline
\end{tabular}

a: Cross breed vs Control; b: Vechur breed vs Control; c: Cross breed vs Vechur breed

response (Bannerman et al., 2003). Hoshino et al., 1999 studied on knockout mice confirmed that TLR4 is critical for LPS signalling. A report by Nomura et al., 2000 reported that TLR4 mRNA expression was decreased within a few hours of LPS treatment in macrophages, whereas this study could not observe the obvious TLR4 mRNA decrease after the LPS treatment. In another report Muzio et al., 2000 described that
LPS increased TLR4 mRNA expression in polymorphonuclear leukocytes and monocytes.

Relative expression of TLR2 and TLR4 genes was found to be significantly $(p \leq 0.01)$ higher in Vechur cattle breed when compared with that of control and crossbreed. Vechur cattle breed are known for its resistance against mastitis, increased expression of TLR genes in Vechur cattle during infection 
could be related to early regression of infection without precipitating into disease. Bramley et al., 1981 also observed that cows that were challenged with live E. coli bacteria showed huge variations in the resistance to mastitis. Joshi and Gokhale, 2006 reported that the genetic makeup of animals leads to the susceptibility to mastitis different from one breed to another. The incidence of mastitis has been found lowest in native breeds of cattle as compared to pure breeds and crossbred cattle. Among the two TLRs studied, the relative expression of mRNA in Vechur cattle was relatively higher for TLR2 (6.90 fold) than TLR4 (4.24 fold). When Gram-negative bacteria infect the host, LPS was recognized by macrophages through the constitutively expressed TLR4. Later, TLR2 is activated directly by LPS or indirectly through secondary cytokines. Through the newly synthesized TLR2, macrophages respond better to LPS or other bacterial components such as lipoproteins that are membranous components of both Gram-positive and Gram-negative bacteria. Hence, higher expression of TLR2and TLR4 might contribute maximum to the innate immune response against the bacteria in Vechur cattle.

\section{Conclusion}

This study implies that the expression of the two presumptive LPS signalling receptor genes TLR2 and TLR4 are differently regulated in Vechur cattle. The expression of TLR2 was higher when compared to TLR4. This may because when gramnegative bacteria infect the host, LPS was first recognized by macrophage, through the constitutively expressed TLR4. Latter TLR2 was activated directly by LPS or indirectly through secondary cytokines. Thus, higher expression of TLR2 and TLR4 might contribute maximum to the innate immune response against the bacteria in Vechur cattle.

\section{Acknowledgment}

The authors acknowledge College of Veterinary and Animal Science for providing the laboratory facilities for the successful completion of this work. The first author acknowledging the Department of Science and Technology for providing INSPIRE Fellowship (IF131025) for the Ph.D program.

\section{References}

Aderema, A., Ulevitch, R.J., 2000. Toll-like receptors. Nature 406, 782-7.

Akira, S., Takeda, K., Kaisho, T., 2001. Toll -Like Receptors. Nature Immunology 2, 675-80.

Almeida, J.R.M., Modig, T., Petersson, A., Hahn-Hagerdal, B., Liden, G., Gorwa-Grauslund, M.F., 2007. Increased tolerance and conversion of inhibitors in lignocellulosichydrolysates by Saccharomyces cerevisiae. Journal of Chemical Technology Biotechnology 82, 340-349.

Anna, C., Marta, M., Katarzyna, K., 2021. TLR4 and CD14 trafcking and its infuence on LPS-induced pro-infammatory signalling. Cellular and Molecular Life
Science 78, 1233-1261

Bannerman, D.D., Paape, M.J., Hare, W.R., Sohn, E.J., 2003. Increased levels of LPS-binding protein in bovine blood and milk following bacterial lipopolysaccharide challenge. Journal of Dairy Science 86, 3128-3137.

Bohan, Y., Qin, L., Min, Z., 2019. LPS-induced upregulation of the TLR4 signaling pathway inhibits osteogenic differentiation of human periodontal ligament stem cells under inflammatory conditions. International journal of Molecular Medicine 4165, 2341-2351

Bramley, A.J., Godinho, K.S., Grindal, R.J., 1981. Evidence of penetration of the bovine teat duct by Escherichia coli in the interval between milkings. Journal of Dairy Research 48, 379-386.

Dixon, D.R., Darveau, R.P., 2005. Lipopolysaccharide heterogeneity. Innate host responses to bacterial modification of lipid A structure. Journal of Dental Research 84, 584-595.

Dziarski, R., Wang, Q., Miyake, K., Kirschning, C.J., Gupta, D., 2001. MD-2enables Toll-like receptor 2 (TLR2)mediated responses to lipopolysaccharide and enhances TLR2-mediated responses to Gram positive and Gramnegative bacteria and their cell wall components. Journal Immunology 166, 1938-1944.

Griesbeck-Zilch, B., Meyer, H.H.D., Kuhn, C., Schwerin, M., Wellnitz, O., 2008. Staphylococcus aureus and Escherichia coli cause deviating expression profiles of cytokines and lactoferrina messenger ribonucleic acid in mammary epithelial cells. Journal of Dairy Science 91, 2215-2224.

Hoshino, K., Takeuchi, O., Kawai, T., Sanjo, H., Gawa, T., Takeda, Y., Takeda, K., Akira,S., 1999. Cutting edge: Tolllike receptor 4 (TLR 4)-deficient mice are hyporesponsive to lipopolysaccharide: evidence for TLR 4 as the LPS gene product. Journal of Immunology 162, 3749-3752. Ibeagha-Awemu, E.M., Lee, J.W., Ibeagha, A.E., Bannerman, D.D., Paape, M.J., Zhao, X., 2008. Bacterial lipopolysaccharide induces increased expression of toll-like receptor (TLR) 4 and downstream TLR signaling molecules in bovine mammary epithelial cells. Veterinary Research 39, 11.

Identification and activation of TLR4-mediated signalling pathways by alginate-derived guluronate oligosaccharide in RAW264.7 macrophages. Scientific Reports 7, 1663.

Jian,W., Yi, S., Yibo, F., Conghui, F., Song, C., Jie, S., Lili, Z., Long, Q., Mengjin, Y., Zhaofen, L., 2016. NF-KB inhibition attenuates LPS-induced TLR4 activation in monocyte cells. Molecular Medicine Reports 5825, 4505-4510

Joshi, S., Gokhale, S., 2006. Status of mastitis as an emerging disease in improved and periurban dairy farms in India. Annals of the New York Academy of Sciences 1081, 74-83.

Kirschning, C.J., Wesche, H., Ayres, M.T., Rothe, M., 1998. Human Toll-like receptor 2 confers responsiveness to bacterial lipopolysaccharide. Journal of Experimental 
Medecine 188, 2091-2097.

Kumar, R., Tiwari, A.K., Chaturvedi, U., Kumar, G.R., Sahoo, A.P., Rajmani, R.S., Saxena, L., Saxena, S., Tiwari, S., Kumar, S., 2012. Velogenicn ewcastle disease virus. Applied Biochemistry and Biotechnology 167, 20052022.

Lemaitre, B., Nicholas, E., Michart, L., Reichhart, J.M., Hoffmann, J.A., 1996. The dorsoventral regulatory gene. Cell 86, 973-983.

Matsuguchi, T., Takagi, K., Musikacharoen, T., Yoshikai, Y., 2000. Gene expressions of lipopolysaccharide receptors, toll-like receptors 2 and 4, are differently regulated in mouse T lymphocytes. Blood 95, 1378-1385.

Medvedev, A.E., Kopydlowski, K.M., Vogel, S.N., 2000. Inhibition of lipopolysaccharide-induced signal transduction in endotoxin-tolerized mouse macrophages: dysregulation of cytokine, chemokine, and Toll-like receptor 2 and 4 gene expression. Journal of Immunology 164, 55645574.

Muzio, M.N., Polentarutti, D., Bosisio, M.K., Prahladan, A., Mantovani, 2000. Toll-like receptors: a growing family of immune receptors that are differentially expressed and regulated by different leukocytes. Journal of Leukocyte Biology 67, 450.

Nomura, F., Akashi, S., Sakao, Y., Sato, S., Kawai, T., Matsumoto, M., Nakanishi, M., Kimoto, M., Miyake, K., Takeda, K., Akira, S., 2000. Cutting edge: endotoxin tolerance in mouse peritoneal macrophages correlates with down-regulation of surface Toll-like receptor 4 expression. Journal of Immunology 164, 3476.

Panigrahi, M., Sharma, A., Bhushan, B., 2014. Molecular characterization and expression profile of partial TLR4 gene in association to mastitis in crossbred cattle. Animal Biotechnology 25, 188-199

Petzl, W.1. , Zerbe, H., Günther, J., Yang, W., Seyfert, H.M., Nürnberg, G., Schuberth, H.J., 2008. Escherichia coli, but not Staphylococcus aureus triggers an early increased expression of factors contributing to the innate defense in the udder of the cow. Veterinary Research 3918.

Philemon, U., Ntombikayise, X., Monde, N., 2091. LPS induces inflammatory chemokines via TLR-4 signalling and enhances the Warburg Effect in THP-1 cells. PLOS ONE $1-17$

Poltorak, A., Smirnova, I., He, X., Liu, M.Y., Van, H.C., McNally, O., Birdwell, D., Alejos, E., Silva, M., Du, X., Thompson, P., Chan, E.K., Ledesma, J., Roe, B., Clifton, S., Vogel, S.N., Beutler, B., 1998. Genetic and physical mapping of the Lps locus: identification of the Toll-4 receptor as a candidate gene in the critical region. Blood Cells Molecular Disease 24, 340-355.

Salwa, R.E., Hiba, S., Fathia, A.M., 2019. Toll-like receptors activation, signaling, and targeting: an overview. Bulletin of the National Research Centre 43, 187.

Schletter, J., Heine, A.J., Ulmer, Rietschel, E.T., 1995. Molecular mechanisms of endotoxin activity. Archive Microbiology
164, 383-389.

Seegers, H., Fourichon, C., Beaudeau, F., 2003. Production effects related to mastitis and mastitis economics in dairy cattle herds. Veterinary Research 34, 475-491.

Shimazu, R., Akashi, S., Ogata, H., Nagai, Y., Fukudome, K., Miyake, K., Kimoto, M., 1999. MD-2, a molecule that confers lipopolysaccharide responsiveness on Toll-like receptor 4. Journal of Experimental Medicine 189, 1777-1782.

Takeuchi, O., Hoshino, K., Kawai, T., Sanjo, H., Takada, H., Ogawa, T., Takeda, K., Akira, S., 1999. Differential roles of TLR2 and TLR4 in recognition of gram-negative and gram-positive bacterial cell wall components. Immunity 11, 443-451.

Thanislass, J., Yuvaraj, G., Antony, P.X., Venkatesa perumal, S., ubba reddy, K.V., 2009. Enhanced expression of TNF- $\alpha$ by the buffalo PBMCs incubated with LPS. Indian Journal of Animal Sciences 80, 528-530.

Theodora, A.M., Annelou, I.P., Van, D.V., Janneke, H., Marcus, J.S., Riekelt, H., Cornelis, Van., Tom, V.D.P., 2019. Platelet Toll-like receptor expression andactivation induced by lipopolysaccharide and

Ulevitch, R.J., Tobias, P.S., 1995. Receptor-dependent mechanisms of cell stimulation by bacterial endotoxin. Annual. Review of Immunology 13, 437-457.

Vidya, M., Kumar, V., Sejian, V., Bagath, M., Krishnan, G., Bhatta, R., 2018. Toll-like receptors: significance, ligands, signaling pathways, and functions in mammals. International Reviews of Immunology 37, 20-36.

Wallet, S., Puri, V., Gibson, F., 2018. Linkage of infection to adverse systemic complications: periodontal disease, toll-like receptors, and other pattern recognition systems. Vaccines 6 , E21.

Weishan, F., Decheng, B., Ruijin, Z., Nan, C., Hong, X., Rui, Z., Jun, L., Min, W., Xu, X., 2017. Identification and activation of TLR4-mediated signalling pathways by alginatederived guluronate oligosaccharide in RAW264.7 macrophages. Scientific Reports 7, 1663.

Yang, R.B., Mark, M.R., Gray, A., Huang, A., Xie, M.H., Zhang, M., Goddard, A., Wood, W.I., Gurney, A.L., Godowski, P.J., 1998. Toll-like receptor-2 mediates lipopolysaccharide-induced cellular signaling. Nature 395, 284-288.

Yang, W., Zerbe, H., Petzl, W., Brunner, R.M., Gunther, J., Draing, C., Aulock, V.S., Schuberth, H.J., Seyfert, H.M., 2008. Bovine TLR2 and TLR4 properly transduce signals from Staphylococcus aureus and E. coli, but $S$. aureus fails to both activate NF-kappaB in mammary epithelial cells and to quickly induce TNF alpha and interleukin-8 (CXCL8) expression in the udder. Molecular Immunololgy, 45

Zuhair, B.I., 2017. Mastitis vaccines in dairy cows: Recent developments and recommendations of application. Veterinary World 10, 1057-1062. 